\title{
Twitter'ın Farklı İletişim Uygulamalarında Eşzamanlı Araçsallaşması: Covid-19 Pandemisinde Dr. Fahrettin Koca'nın Twitter Paylaşımlarının Analizi
}

\author{
DOI: $10.26466 /$ opus. 884602
}

*

\author{
A Elif Posos Devrani * \\ * Dr. Öğretim Üyesi, Türk-Alman Üniversitesi, Kültür ve Sosyal Bilimler Fakültesi, Kültür ve \\ İletişim Bilimleri Bölümü İstanbul/Türkiye \\ E-Posta: posos@tau.edu.tr \\ ORCID: $\underline{0000-0002-9550-3879}$
}

\begin{abstract}
Öz
Sosyal medya ve sosyal ă̆ platformları, farklı stratejik iletişim uygulamalarında kanal ve araç olarak yer alabilmektedir. Bir sosyal ă̆ platformu olarak Twitter, gündemin gereklilikleri bağlamında eş zamanlı olarak farklı alanlardaki iletişim uygulamalarında araç olarak kullanılabilmektedir. Bu makalede, 10 Ocak-31 Mayıs 2020 tarihleri arasında T.C. Sağlık Bakanı Dr. Fahrettin Koca'nın Twitter'ı sağlık iletişimi, kriz iletişimi ve siyasal iletişim uygulama alanlarında araçsallaştırması incelenmiştir. Araştırma, iki düzeyde gerçekleşmiştir. Illk düzeyde, Dr. Fahrettin Koca'nın paylaşımları sayısal analize tabi tutulmuştur. Uzun dönemde (Kasım 2018-Ocak 2021) paylaşım, beğeni ve yeniden paylaşım sayılarında farklılık yaşanıp yaşanılmadığına bakılmıştır. İkinci düzeyde ise, kriz öncesi ve kriz esnasındaki yönetimin önemli tarihleri olan 10 Ocak-31 Mayıs 2020 arasındaki 757 paylaşım refleksif tematik analiz yöntemiyle incelenmiştir. Analiz sonucunda, Dr. Fahrettin Koca'nın paylaşımlarının her üç farklı uygulama alanında da araçsallaştırıldığ̀ görülmüştür. Ülke gündemine ve dünya gündemine göre paylaşımların beğeni ve yeniden paylaşım sayılarının azalma ya da artış gösterdiği ortaya çıkmıştır.
\end{abstract}

Anahtar Kelimeler: sosyal medya, siyasal iletişim, kriz iletişimi, sağlık iletişimi, Covid-19 


\title{
Simultaneous Instrumentation of Twitter in Different Communication Practices: The Analysis of Dr. Fahrettin Koca's Twitter Posts in Covid-19 Pandemic
}

\begin{abstract}
Social media can take place as channels and tools in different strategic communication practices. As a social network platform, Twitter can be used as a communication tool/channel in various fields simultaneously in the agenda's requirements. In this article, between January 10 and May 31, 2020, health minister of Turkey Dr. Fahrettin Koca's instrumentalization of Twitter in health communication, crisis communication, and political communication practices has been examined. The research took place at two levels. At the first level, Dr. Fahrettin Koca's posts were subjected to numerical analysis. In the long term (November 2018-January 2021), it was examined whether there was a difference in the number of shares, likes, and retweets during the pre-/crisis period. At the second level, 757 shares between January 10 - May 31, 2020, which are important dates before and during the crisis management, were analyzed using the reflexive thematic analysis method. As a result of the analysis, it has been seen that Dr. Fahrettin Koca's posts are instrumentalized in all three different strategic communication practice areas. According to the country's agenda and the world agenda, it has been revealed that the number of likes and reposts of the posts decreased or increased.
\end{abstract}

Keywords: Social media, political communication, crisis communication, health communication, Covid19 


\section{Giriş}

Sosyal medya, farklı iletişim stratejileri uygulamalarında farklı amaçlarla kullanılan bir kitle iletişim aracı haline gelmiştir. Dünya çapında, sosyal medya kullanıcı sayısı 4,2 milyara ulaşmış olup, bu oran tüm dünya nüfusunun \%53'üne tekabül etmektedir (Hootsuite ve We are Social, 2021). Türkiye'deki sosyal medya kullanıcı sayısı ise son araştırmalara göre 60 milyon olup, genel nüfusun \%70.8'ine tekabül etmektedir. Hootsuite ve We are Social'nn \#Digital2021 Turkey isimli raporunda, son bir yıl içerisinde sosyal medya kullanıcısı sayısında Türkiye'de yüzde 11 oranında bir artış olduğu belirlenmiştir. Aynı kaynağa göre, Twitter kullanıcı sayısı ülkemizde 13,6 milyondur (Hootsuite ve We are Social, 2021).

Bu makalede, bir kriz döneminde, tanınmış bir siyasal figürün, T.C. Sağlık Bakanı Dr. Fahrettin Koca'nın, sağlık alanındaki yetki ve yetkinliğini halka aktardığı bir dönemde, sosyal ağ platformlarından biri olan Twitter üzerinden yürüttüğü iletişim incelenecek ve bu sosyal ağ platformunu stratejik iletişimin farklı uygulama alanlarında araç olarak kullanılıp kullanılmadığı araştırılacaktır. Dr. Fahrettin Koca ve ekibi, politik kimliği sebebiyle siyasal iletişim uygulamalarını, bakanlık yaptığı alan itibarı ile sağlık iletişimi uygulamalarını, tüm dünyayı etkisi altına alan Covid-19 sağlık krizi sebebiyle de kriz iletişimi uygulamalarını eş zamanlı ve entegre şekilde yürütmek durumunda kalmıştır. Eş zamanlı yürütülmesi gereken farklı stratejik iletişim planlarında, Twitter'ın araçsallaştırılması araştırmanın odağını oluşturmaktadir.

Araştırmanın ana hatlarına geçmeden önce, araştırma sorusunun etrafında şekillendiği kavramları sosyal medya ekseninde anmak isterim.

"İletişim" ana disiplinin altında yer alan siyasal iletişim, sağlık iletişimi ve kriz iletişimi uygulama alanları, kullandıkları yöntemler ve araçlar anlamında benzerlik taşısalar da, odaklandıkları sorunsallar ve hedefler noktasında birbirlerinden çok farklı hedef kitlelere hitap etmeleri de mümkün olan çalışma alanlarıdır.

Stratejik iletişim uygulama alanlarından sağlık iletişiminin Schiavo tarafından yapılan güncel ve geniş tanımlarından birini hatırlamakta fayda vardir:

- Să̆lık iletişimi farklı kitlelere ulaşmak ve sağhlkla ilgili enformasyonu; bireyleri, cemaatleri, sağlık profesyonellerini, özel grupları, politika üretenleri ve 
halkı etkileme, işin içine katma ve destekleme amacı ile sonucunda sağllk çıtılarını geliştirecek bir davranışı, uygulamayı ya da siyasayı savunmak, sunmak, benimsemek ya da sürdürmek için paylaşan çok yönlü ve çok disiplinli bir yaklaşımdır." (Schiavo'dan akt. Çınarlı, 2016).

Sağlık iletişiminde sosyal medya kullanımı, kurum ve hedef kitle arasında stratejiye uygun olarak tek yönlü ya da çift yönlü iletişimi mümkün kılması, daha da önemlisi bu iletişimi hızlandırması açısından araç olarak sıklıkla kullanılmaktadır. Halk sağlığı odaklı iletişim çalışmaları kapsamında sosyal medyayı doğru bir kanal olarak konumlandırabilmek, şu karakteristik özellikleri sağlamak ile mümkündür (Heldman vd., 2013, s. 3-4)

- Geleneksel halk sağlığı iletişim kanalları ile sosyal medya kanallarını bütünleştirmek

- Farklı kitleleri hedefleyebilmek ve onlara ulaşabilmek

- Halk sağlığı bilgilerini yeni alanlarda erişilebilir kılmak

- Gerçek zamanlı dönüt alabilmek ve bu dönütleri değerlendirebilmek

- Doğrudan katılımı - stratejinin elverdiği şekilde - mümkün kılmak

Kriz iletişimi ise stratejik iletişimin uygulama alanlarından bir diğeridir. Dünyanın ekonomik, siyasi, iklimsel vb. birçok faktör sebebiyle krizlerin daha sık ve daha olası yaşanılan bir yer haline gelmesi, kriz iletişiminin gerektiğinde devreye alınan bir acil durum planı olmaktan çıkıp, süreklilik arz eden bir iletişim şekline dönüşmesini zorunlu k1lmaktadır (Coombs, 2014, s. 16). Bu süreklilik, krizi yönetecek iletişim uzmanlarının sadece kriz anında değil, kriz öncesinde ve sonrasında da kriz yönetimine entegre edilmiş bir stratejik bir iletişim planını uygulamalarına bağlıdır (Coombs ve Holladay, 2012, s. 46). Sosyal medyanın kriz iletişiminde edindiği uygulama alanlarını Wendling vd. 12 başlıkta toplamıştır (Wendling vd.'nden akt. Ateş ve Baran, 2020):

- Riskler ve krizler konusunda kamu bilincini arttırmak,

- Gözetim, izleme, durum farkındalığı ve erken uyarı sistemi,

- Hazırlıkların geliştirilmesi,

- Bilgi sağlayan ve uyaran,

- Gönüllüleri seferber ederek krizlere çözüm artırmak,

- Kurbanların ve kurtulanların belirlenmesi,

- İtibar yönetimi,

- Finansman ve destek için teşvikin sağlanması,

- Eski yazılanlar hakkında bilgi edinmek, 
- Milli ve uluslararası oyuncular arasında, kamu aktörleri ve kamuya ait olmayan aktörler arasında ortaklığı ve iş birliğini geliştirmek,

- Güven oluşumu,

- Kurtarma yönetimi geliştirilmesi

Siyasal iletişim ise, McNair'e göre siyasal bir amaç güdülerek planlı şekilde gerçekleştirilen, iletişimin tüm formlarını kapsayan bütüncül bir uygulama alanıdır (McNair, 2017, s. 4). Aziz, siyasal iletişimde internetin, siyasi aktörler tarafından (partiler, adaylar, politikacılar vb.) kendilerini tanıtmak ve bilgi aktarmak için sıklıkla kullanıldığını söyler (Aziz, 2014). İnternetin ve sosyal medyanın iki yönlü iletişimi mümkün kılan yapısı, siyasal aktörlerin hedef kitleleri ile yeni iletişim teknolojileri ve bu makale özelinde bir sosyal ağ platformu olan Twitter aracıllğ 1 ile haberleşmelerine imkan vermekle kalmaz, hedef kitlenin nabzının tutulabilmesini de kolaylaştırır (Aziz, 2011). Sosyal medyanın, geleneksel medyada ya da yüz yüze verilen mesajların yeniden üretilip yaygınlaşmasına imkân verdiğinin altını çizen Aziz, bu özellikleri sebebiyle internetin süreklilik arz eden bir siyasal iletişim aracı olarak kullanıldığını belirtir (Aziz, 2014). Aziz, siyasal iletişim türlerini amaçlarına göre dörde ayırır (Aziz, 2014, s. 39-45):

\section{Kurum İçi Siyasal İletişim}

İki boyutlu olan kurum içi siyasal iletişim, bir boyutuyla kurum içine özgü günlük politikaların oluşturulmasını konu alırken, diğer boyutuyla dışa yönelik siyasal mesajların öncelikle kurum içinde bilinmesi ve içselleştirilmesini konu alır. Haber verme içselleştirme süreçleri, sosyal ağ platformlarında aynı kurum içinde yer alan siyasal aktörlerin birbirleriyle etkileşim halinde oldukları paylaşımlarda da görülebilir.

\section{Ülke İçi Siyasal İletişim}

Aziz, bu konuda özellikle internet ve sosyal medyanın iletişiminde önemli bir aktör olduğu günümüzde, her ne kadar ülke içini ilgilendiren ve hedef kitle olarak ülke içindeki kurum ve kişileri gören mesajlar üretilse de, bu mesajların kullanılan kanal ve araçlar sebebiyle ülke dışında da yankı bulabileceği notunu düşer. 


\section{Uluslararası Siyasal İletişim}

Küreselleşmeyle birlikte önemini arttıran uluslararası siyasal iletişim, kitle iletişim araçlarının gelişimi sebebiyle iç siyasal iletişimde kullanılan her yöntemin, tekniğin, kanalın ve medyanın izdüşümünün görüldüğü bir alan haline gelmiştir.

\section{Uluslararası Siyasal Örgütler İletişimi}

Birleşmiş Milletler, Avrupa Birliği, NATO, Avrupa Konseyi vb. ulus üstü ve siyasi arenada söz hakkı olan kuruluşlarla inşa edilen iletişim, bu kategoride değerlendirilir.

Şimdiye dek kısaca bahsettiğimiz iletişim uygulamaları alanlarının ortak özelliği, kanal ve araç olarak yeni kitle iletişim araçlarının kullanımı esnasinda birbirleriyle örtüşen hedef kitleleri hedeflemeleridir. Diğer bir deyişle, aynı kanal ve araç vasıtasıyla, bir siyasal aktör hem sağlık, hem kriz hem de siyasal iletişimdeki hedef kitlesine seslenebilmekte, bunu eş zamanlı yapabilmektedir.

Makalenin devamında, tek platform üzerinden çoklu amaca hizmet eden bir sosyal ağ platformunun, çok amaçlı araç olarak kullanımı irdelenecektir. Covid-19 pandemisinin Türkiye'yi etkilediği ilk dönemlerde, hem siyasal iletişim, hem sağllk iletişimi hem de kriz iletişimi kapsamında hedef kitlesine mesajlarını ileten T.C. Sağlık Bakanı Dr. Fahrettin Koca'nın Twitter hesabındaki paylaşımları bu farklı iletişim uygulamaları alanları bazında incelenecektir.

\section{Yöntem}

Araştırmada yöntem olarak karma yöntem kullanılmıştır. İki düzeyde yapılan analizlerde, birinci düzeyde daha geniş zaman aralığında Dr. Fahrettin Koca'nın Twitter hesabının (@drfahrettinkoca) paylaşım/beğeni/yeniden paylaşma verilerine aylık bazda nicel olarak bakılmıştır. İkinci düzeyde ise, kriz dönemi olarak tanımlanan 10 Ocak - 31 Mayıs 2020 tarih aralığındaki 3198 paylaşım refleksif tematik analize tabi tutulmuştur.

Braun ve Clarke, ilk olarak 2006' da psikoloji alanına ve nitel verilerin analizine odaklanan bir araştırma yöntem çalışmasını sunmuş ve tematik analize esnek bir yaklaşım getirmiştir (2006). Braun, Clarke vd'ne göre tematik analiz çalışmalarında üç ana yaklaşım bulunmaktadır (Braun et al., 2019): 
Kod güvenilirliği yaklaşımı: Birden fazla kodlayıcının birlikte çalıştığı büyük projelerde amaca hizmet ettiği takdirde büyük kolaylık sağlayan bu yaklaşımda kodlar çalışma öncesinde yapılan literatür taramasında belirlenir. Çalışmanın merkezinde güvenilir ve tutarlı bir veri kodlaması gerçekleştirmek vardır. Çalışmayı gerçekleştirecek araştırmacıların takip edebileceği nesnel bir kod seti bulunmaktadır. Araştırmacının öznel bakış açısı sürece ve sonuçlara yansimaz. (Boyatzis, 1998; Guest et al., 2012)

Yapılandırılmış kod seti yaklaşımı: Kod güvenilirliği yaklaşımı ile refleksif tematik yaklaşımı arasında bir noktada bulunan yapılandırılmış kod seti yaklaşımı, kodların yapılandırılması açısından kod güvenilirliği yaklaşımıyla benzerlik gösterirken, temel kabul ettiği nitel felsefesi refleksif yaklaşımla benzeşir. Bu yaklaşımla yapılan çalışmaların başında, kodların tamamı olmasa da bir kısmı belirlenmiştir ve temaların alan özetleri ile benzeşen isimlere sahip olması beklenir. Braun vd, bu şemsiye kavramın gölgesinde çerçeve analizi, şablon analizi ve matris analizini de konumlandırır.

Refleksif yaklaşım: Temalar, analizi gerçekleştiren kişi tarafından şekillendirilir. Veri analizi sırasında kodlar değişebilir, birleşebilir, yeniden adlandırılabilir. Analizin en başından itibaren sabitlenmiş bir kod kitabı/kategori/tema bulunmamaktadır.

Braun ve Clarke ilk çalışmalarından yaklaşık 13 sene sonra, hem bu süre içerisindeki doğru/yanlış ve farklı uygulamaları derleyip, hem de kendi yaklaşımların değişime ve gelişime açık tutarak çalışmalarının yeni bir sürümünü alanyazına kazandırdılar (2019). Tematik analizde takip edilen yol 6 başlıkta özetlenebilmektedir:

1. İçeriğe aşinalık

2. Kodların belirlenmesi

3. Temaların oluşturulması

4. Temaların gözden geçirilmesi

5. Temaların tanımlanması ve adlandırılması

6. Rapor yazımı

Makaleye konu araştırmada, bu altı süreç takip edilmiştir.

\section{Veri Toplama ve Analiz Aracı}

Dr. Fahrettin Koca'nın Twitter platformundaki paylaşımları, Twitonomy uygulaması kullanılarak ham veri olarak elde edilmiştir. Veri seti, ikincil bir 
kaynak uygulama olarak seçilen Visinitas vasıtasıyla kontrol edilmiş, herhangi bir veri kaybının bulunmadığı teyit edilmiştir. Ayrıca, Dr. Fahrettin Koca'nın takipçi sayısındaki değişiklikler için SocialBlade isimli uygulamaya başvurulmuştur. Twitonomy ile elde edilen ve Visinitas'dan elde edilen veriler ile karşılaştırılan paylaşım içerikleri ve bilgileri, Excel'e aktarılarak nicel ve nitel analizler gerçekleştirilmiştir. Dr. Fahrettin Koca'nın Twitter hesabındaki paylaşımlara dair veri toplama tarihi 19 Ocak 2021 olmuştur.

\section{Örneklem}

Dr. Fahrettin Koca'nın Twitter paylaşımları iki farklı ana düzlemde incelenmiştir. İlk olarak 26 Kasım 2018 - 19 Ocak 2021 tarihleri arasındaki paylaşımın aylara göre sayısı ve paylaşımlarının aldığı etkileşimler nicel olarak karşılaştırılmıştır. Dr. Fahrettin Koca, Twitter'a 9 Temmuz 2018 tarihinde girmiş olmasına rağmen, veri toplama aracı olarak kullanılan Twitonomy, en güncel paylaşımlardan en fazla 3200 tanesini Twitter veri tabanından çekebilmektedir. Bu sebeple, araştırmanın ilk fazındaki sınırlılıkla karşılaşılmış, 26 Kasım 2018- 19 Ocak 2021 tarihleri arasında Dr. Fahrettin Koca tarafından paylaşılan 3198 paylaşıma dair analiz yapılmıştır. Yine de, incelenen tarih aralığı, Dr. Fahrettin Koca'nın pandemi öncesi Twitter kullanımı ile, pandemi sırasında sağlık iletişimi ve kriz iletişimi aracı olarak Twitter'1 kullanırken yaptığı paylaşımlarının ve etkileşimlerin sayısal değişimine dair anlamlı sonuçlar vermektedir.

İkinci olarak, 10 Ocak -31 Mayıs 2020 tarihleri arasında Dr. Fahrettin Koca tarafından yapılan paylaşımları hem içerik hem de etkileşim bazında incelenmiştir. Bu tarih aralığı belirlenirken, Türkiye'de Covid-19'daki seyri dikkate alınmıştır. Bilindiği üzere, Covid-19 vakası Türkiye'de ilk kez 11 Mart 2020 tarihinde görülmüştür (Sağllk Bakam Koca Türkiye'de İlk Koronavirüs Vakasının Görüldü̈̆̈̈̈nü Açıkladı, 2020). Ancak Sağlık Bakanlığı'nın proaktif kriz yönetimi anlayışının bir sonucu olarak 10 Ocak 2020 tarihinde Covid-19 pandemisini yönetmek üzere Bilim Kurulu kurulmuştur (Yener, 2020). Bu sebeple, Covid-19 pandemisine yönelik atılan kriz öncesi adım olan Bilim Kurulu'nun kurulma tarihi, tematik analizin başlangıç tarihi olarak belirlenmiştir. Amaç, kurumsal düzeyde atılan adımın stratejik iletişim uygulamalarında karşılığ1nın olup olmadığını görebilmektir. Analizin bitiş tarihi ise, sokağa çıkma k1sttlamalarının bittiği ve normalleşme sürecinin tamamlandığ 2020 Mayıs 
sonu olarak belirlenmiştir. Tematik analizde incelemelerinde sağlık iletişimi, kriz iletişimi ve siyasal iletişimle ilintili sekiz tema belirlenmiş, söz konusu tarih aralığındaki 757 paylaşım incelenerek temalara ayrılmıştır.

\section{Bulgular}

\section{Düzey: Nicel Analiz}

T.C. Sağlık Bakanı Dr. Fahrettin Koca, 9 Temmuz 2018 tarihinde Twitter' daki hesabını aktif hale getirmiştir. O tarihten bu yana, Dr. Koca'nın en çok takipçi kazandığı zaman dilimi Türkiye'deki ilk vakanın görüldüğü ay olan 2020 y1lının Mart ayı olmuş, bir ay içerisinde 3,919,175 hesap Dr. Koca'yı takip etmeye başlamış, 19 Ocak 2021 tarihi itibarı ile takipçi sayısı 6,800,000'i aşmıştır (SocialBlade.com, 2020).

Dr. Fahrettin Koca'nın etkileşimlerine bakıldığında, en çok etkileşimde bulunduğu hesapların Cumhurbaşkanı Recep Tayyip Erdoğan, İletişim Başkanı Fahrettin Altun, Sağlık Bakanlığı ve Cumhurbaşkanlığı olduğu görülmektedir. Bu etkileşim karnesi, Dr. Fahrettin Koca'nın siyasal iletişimin amaca göre kategorileştirilmesinde bahsedilen "kurum içi siyasal iletişim" alanına örnek teşkil etmektedir. Etkileşimlerin nicel ayrıntıları Tablo 1'de paylaşılmaktadır.

Tablo 1. Dr. Fahrettin Koca'nın Twitter'da 26 Kasım 2018 - 19 Ocak 2021 tarihleri arasında en sik etkileşimde bulunduğu hesaplar ve hashtagler

\begin{tabular}{ll}
\hline En Çok Yeniden Paylaşılan (Retweet) & Sayısı \\
\hline @RTErdogan & 80 \\
\hline @fahrettinaltun & 9 \\
\hline @saglikbakanligi & 5 \\
\hline @bestepe & 4 \\
\hline @AACanli & 4 \\
\hline @Akparti & 3 \\
\hline En Çok Bahsedilen (Mention) & Sayısı \\
\hline @RTErdogan & 16 \\
\hline @suleymansoylu & 12 \\
\hline @ziyaselcuk & 6 \\
\hline @hans_kluge & 6 \\
\hline @tusebgovtr & 3 \\
\hline @muratkurum & 3 \\
\hline En Çok Kullanılan Hashtagler & Sayısı \\
\hline \#minnettariz & 14 \\
\hline \#deprem & 10 \\
\hline \#hayatevesigar & 9 \\
\hline
\end{tabular}




\begin{tabular}{ll}
\hline \#barışpinariharekatı & 6 \\
\hline \#riskigörün & 6 \\
\hline \#birlikteyeneceğiz & 5 \\
\hline \#millitakım & 4 \\
\hline \#türkiyeninotomobili & 4 \\
\hline \#29ekim & 4 \\
\hline \#30ă̆ustos & 4 \\
\hline
\end{tabular}

Dr. Fahrettin Koca'nun 26 Kasım 2018 - 19 Ocak 2021 arasındaki paylaşımları incelendiğinde, Şekil.1'de de görselleştirildiği gibi Ocak 2020' den itibaren paylaşım sayılarının arttığı ve 136-227 bandında paylaşım yapıldığı görülmektedir.

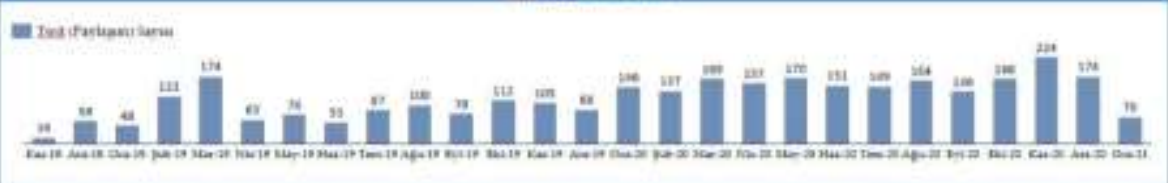

Şekil 1. Dr. Fahrettin Koca'nın Twitter'da 26 Kasım 2018- 19 Ocak 2021 tarihleri arasindaki aylık paylaşım sayısı

Dr. Fahrettin Koca'nın paylaşımlarına gösterilen etkileşimlere like (beğeni) ve retweet (tekrar paylaşma) olmak üzere iki kategoride bakılmıştır. Şekil 2' de görülebileceği gibi, Bakan Koca'nın paylaşımlarının en çok beğeni aldığı ay, Türkiye'de ilk vakanın açıklandığı ve Covid-19'un ülkedeki seyri ile alınan önlemlere dair ilk açıklamaların yapıldığı 2020 yılının Mart ayı olmuştur.

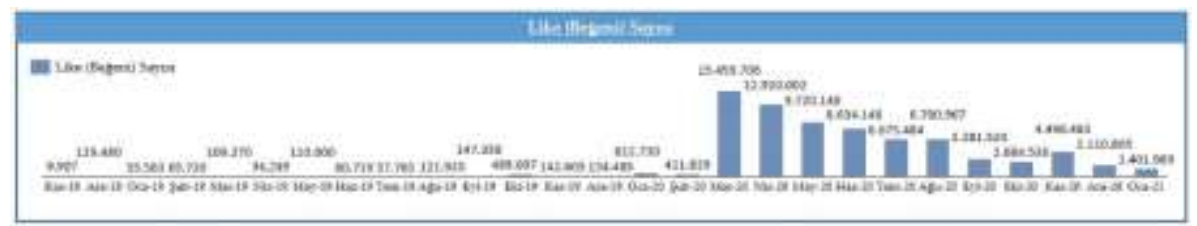

Şekil 2. Dr. Fahrettin Koca'nın Twitter'da 26 Kasım 2018-31 Mayıs 2020 tarihleri arasındaki aylık like (beğeni) sayısı

Dr. Fahrettin Koca'nın paylaşımlarının tekrar paylaşılma sayılarına baktığımızda ise like (beğeni) analizindeki ile çok benzer bir sonuç olduğunu görürüz: En çok retweet (tekrar paylaşma) 2020 yılının Mart ayında gerçekleşmiştir. 


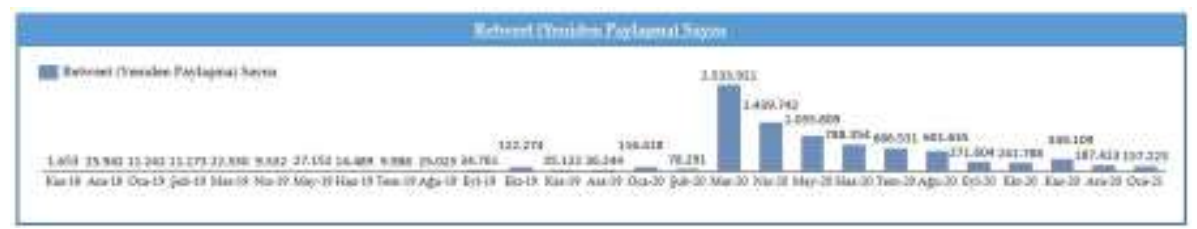

Şekil 3. Dr. Fahrettin Koca'nın Twitter'da 26 Kasım 2018- 19 Ocak 2021 tarihleri arasındaki aylık retweet (tekrar paylaşma) sayısı

Şekil 2 ve Şekil 3'te görülen bir diğer benzerlik, beğeni ve tekrar paylaşılma sayılarının zamanla düşüş̧e geçtiği, ancak kriz iletişimi ve sağlık iletişiminde araç olarak kullanım etkinliğinin arttığı Mart 2020'den önceki dönemlerdeki görece düşük sayılara inmediğidir. Bu durum, Mart 2020 tarihi itibarı ile Dr. Fahrettin Koca' nın yaptığı paylaşımların güvenilir bilgi olarak görülüp yeniden paylaşılmasında büyük bir artış olduğunu göstermektedir. Başka bir deyişle, bu paylaşımlar sağlık iletişiminde ve kriz iletişimindeki prensiplerden biri olan "doğru bilgiyi verme ve yayma" amacına hizmet eden araçlar olmuştur.

\section{Düzey: Tematik Analiz}

10 Ocak -31 Mayıs 2020 tarihleri arasında Dr. Fahrettin Koca'ya ait Twitter hesabından yapılan 3198 paylaşım refleksif tematik analize tabi tutulmuştur. Önce tüm paylaşımlar okunmuş ve kodlar belirlenmiştir. İkinci bir okumada kodların bazıları birleştirilmiş, bazıları ise değiştirilmiştir. Kod çalışmasının akabinde, kodların dahil olduğu sekiz tema belirlenmiştir. Bu sekiz temanın tanımları ve adlandırılması aşağıdaki gibidir:

Genel Gündem: Dünyada ve Türkiye'de yankı uyandıran, gündem dahilinde konuşulan konular, anma, tebrik, teşekkür

Bakanlık gündemi: T.C. Sağlık Bakanlığı' na tabi gündem (Bakanlık toplantıları, işbirliği haberleri vb.)

Parti gündemi : Adalet ve Kalkınma Partisine tabi gündem (Parti toplantıları, ziyaretler, etkinlikler)

Sağlık Farkındalık: Toplumun sağlık konusunda farkındalığı arttıran paylaşımlar (Sigarayı bırakma, egzersiz vb.) 
Covid-19 / Durum: Covid-19 günlük tablo paylaşımları

Covid-19 / Duyuru: Pandemi ve kriz yönetimi kapsamında alınan önlemlerin, dünyadan örneklerin ve ülkeden uygulamaların paylaşıldığı duyurular

Covid-19 / Vefat : Covid-19 yüzünden kaybedilen ünlü simalara, sağlık çalışanlara dair taziye mesajları

Covid-19 / Farkındalık: Toplumda Covid-19'dan korunmak için nelere dikkat edilmesi gerektiğine dair farkındalığı arttırmak adına öneriler ve telkinler, yalan haberlere getirilen düzeltmeler

\section{Aylik Sayısal Analiz}

Temalara dair analizlere geçmeden önce, Dr. Fahrettin Koca'nın Twitter hesabının Bilim Kurulu'nun kurulduğu 10 Ocak 2020'den, kısıtlamaların kaldırıldığı 31 Mayıs 2020 tarihine dek paylaşım sayısı ve paylaşımlara gelen etkileşimlerin sayısal analizine bakmak faydalı olacaktır.

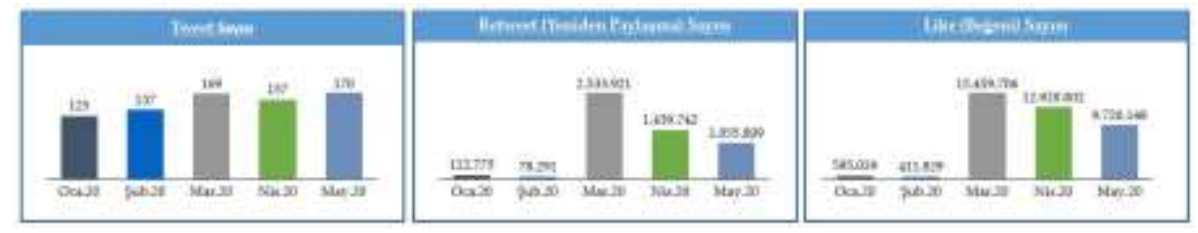

Şekil 4. Dr. Fahrettin Koca'nın Twitter'daki hesabına ait 10 Ocak-31 Mayıs 2020 tarihleri arasındaki aylik twit (paylaşım) / retweet (tekrar paylaşma) / like (beğenme) sayilar

Şekil 4'te görüldügü gibi, Dr. Fahrettin Koca'ya ait hesaptan yapılan paylaşımlarda radikal bir artış olmamıştır. Ancak paylaşım sayılarına dair daha önce Şekil 1'de yer verilen genel sayıları unutmamak, Dr. Koca'nın Ocak 2020 öncesindeki paylaşım sayısının görece daha az olduğunu dikkate almak gerekir. Covid-19 pandemisinin getirdiği krizde, Dr. Koca Ocak 2020' den itibaren pandemi hakkında paylaşımlarına başlamış, kriz yönetiminde Sağlık Bakanlığının yürüttüğü proaktif yaklaşım, iletişim uygulamasında da sergilenmiştir.

Yine Şekil 4'e bakıldığında, Türkiye'de ilk vakanın görüldüğü Mart 2020'den itibaren yeniden paylaşma ve beğeni sayılarının arttığı görülmekte- 
dir. Bu durum, Twitter kullanıcılarının Dr. Fahrettin Koca'yı pandemi konusunda güvenilir bir kaynak olarak konumlandırdığını ve bu hesaptan paylaşlan bilgileri yeniden dolaşıma soktuğunu göstermektedir. Sağlık iletişimi stratejisinde Twitter' 1 bu dönem içerisinde doğru ve hedef kitleye ulaşan bir araç olduğunu söylemek mümkündür.

\section{Tematik Paylaşımların Aylara Göre Dağılımı}

Dr. Fahrettin Koca'nın hesabından yapılan paylaşımların temalara göre aylık dağılımına baktığımızda, kriz iletişimi, sağlık iletişimi ve siyasal iletişim stratejilerinde Twitter'ın nasıl araçsallaştı̆̆ını görebiliriz. Şekil 5 'te görülebileceği gibi, Covid-19'un henüz ülkemizde görülmediği, ancak Bilim Kurulunun kurulması gibi proaktif kriz yönetimi adımlarının atıldığı dönemde, Bakan Koca'nın paylaşımlarında bakanlık gündemi ve parti gündemi temasına ilişkin paylaşımlar başta gelmektedir. Dolayısıyla bu ayda Twitter kullanımının ağırlıklı olarak siyasal iletişim stratejisinde - hatta amaca göre kategorileştirirsek kurum için siyasal iletişimde - bir araç olarak kullanıldığını söylemek mümkündür. Öte yandan, alınan önlemler, uygulamalar, kısıtlamaların yer aldığ 1 Covid-19 Duyuru temasına ilişkin paylaşımların görünürlüğü, Ocak ayından itibaren ( $\mathrm{N}=14$ ) bulunmaktadır. İlgili temada değerlendirilen paylaşımlarda, Dünyada ve Türkiye' deki gelişmeler paylaşılmış, alınan önlemlerle ilgili bilgiler verilmiş, şüpheli vakalarla ilgili gelişmeler aktarılmıştır. Covid19 Duyuru temasına ilişkin paylaşımlar Şubat 2020'de ( $\mathrm{N}=50)$ artmıştır. $\mathrm{Bu}$ da, proaktif kriz iletişimi stratejisinde Twitter'ın araç olarak kullanıldığını gösterir. Illk vakanın görülmesiyle birlikte, Covid-19 Duyuru sayısında düşüş yaşanmış, ancak kriz iletişimi stratejisinde araç olarak kullanımı devam etmiştir.

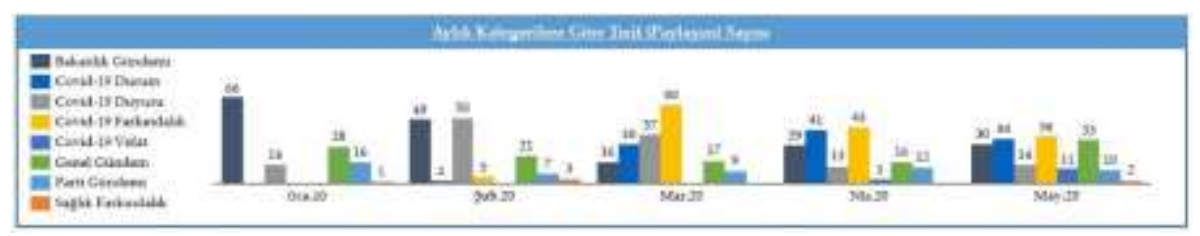

Şekil 5. 10 Ocak-31 Mayıs 2020 tarihleri arasındaki paylaşımlarnn temalara göre aylık dağılımı

Yine Şekil 5'te görülebileceği üzere, Şubat 2020 itibarı ile Covid-19 ve Bakanlık Gündemi temalarındaki paylaşım sayıları çok yakındır. Dolayısıyla bu 
ayda Twitter' $1 n$ hem kriz hem de siyasal iletişimde benzer oranda araçsallaştırıldığg görülmektedir. İlk vakanın görüldügü̈ Mart 2020' den itibaren ise, Covid-19 Farkındalık teması ön plana çıkmaktadır. Bu tema bünyesindeki paylaşımların içerikleri pandemiye ilişkin alınabilecek kişisel önlemler, Covid-19 ve semptomları hakkında bilgilendirme, korunma yolları ile ilgili nesnel bilgiler paylaşma ve bu yönde motive etme olarak özetlenebilir. Dolayısıyla, Mart ayından başlayarak, Mayıs 2020 sonuna dek Twitter sağlık iletişimi stratejisinde önemli bir araç olarak kullanılmış, halk sağlığına ilişkin yeni ve önemli bilgiler bu vasıtayla yeni mecralarda görünür ve erişilebilir k1lınmıştır. Bu temaya ilişkin en yoğun paylaşım Mart ayında yapılmış $(\mathrm{N}=60)$, tema Nisan ( $N=43$ ) ve Mayıs $(\mathrm{N}=36)$ aylarında da dağılımda önemli bir paya sahip olmuştur.

Covid-19 Durum temasına ilişkin paylaşımların Mart ayından itibaren neredeyse sabit bir sayıda kaldığı görülmektedir. Günlük Covid-19 tablosunun paylaşımlarının bu temada olduğu düşünülürse, bazı günlerde yapılan mükerrer paylaşımlar sebebiyle ufak sapmalar yaşansa da aylık olarak benzer sayıda paylaşımların görülmesi beklenendir. Bu tema bünyesindeki paylaşımlar, Twitter'ın Türkiye' deki ilk vakanın görülmesini takiben şeffaf bir bilgi paylaşımına hizmet ederek kriz iletişimi stratejisine katkı sağlamıştır.

Dr. Fahrettin Koca'nın Twitter paylaşımlarında Bakanlık gündemi ve parti gündemi temaları altında değerlendirilen paylaşımlar, Ocak-Mayıs 2020 arasinda mevcudiyetini muhafaza etmektedir. Ocak 2020 sonrasında kriz öncesi ve krizin ilk ayında sayı olarak düşüşte olsa da, siyasal iletişimde araç olarak varlığını devam ettirmiştir. Paylaşımlardaki bu durum, internetin siyasal iletişimde süreklilik arz eden bir iletişim aracı olarak kullanımına örnektir.

\section{Tematik Paylaşımların Beğeni ve Yeniden Paylaşım Dağılımı}

Dr. Fahrettin Koca'nın Ocak-Mayıs 2020 tarihlerinde yaptığı paylaşımların sekiz tema altında değerlendirmesinde, son olarak temaların aldığı etkileşim ve toplam paylaşımlar içerisindeki ağırlı̆̆ını göstermek isterim.

Şekil 6'da görülebileceği üzere, Bakanlık gündemine ilişkin paylaşımlar küçük bir farkla da olsa en çok sayıda paylaşım yapılan tema konumundadır ( $\mathrm{N}=190)$. Bu temayı Parti gündemi teması ile birlikte değerlendirdiğimizde $(\mathrm{N}=54)$, kriz öncesi ve kriz döneminde bile anlamlı bir paya sahip olan bu 
paylaşımların siyasal iletişim stratejilerinde önemli bir araç konumunda olduğu söylenebilir. Ancak bu aracın ve paylaşılan içeriğin etkileşim sayıları, diğer temalara göre daha düşük kalmaktadır. Kriz öncesi ve kriz sırasında kriz iletişimine ve sağlık iletişimine dair temaların etkileşim alması, söz konusu zaman diliminde kriz ve sağlık iletişiminde Twitter'ın araçsallaşmasının daha etkin sonuçlar doğurduğunu göstermektedir.

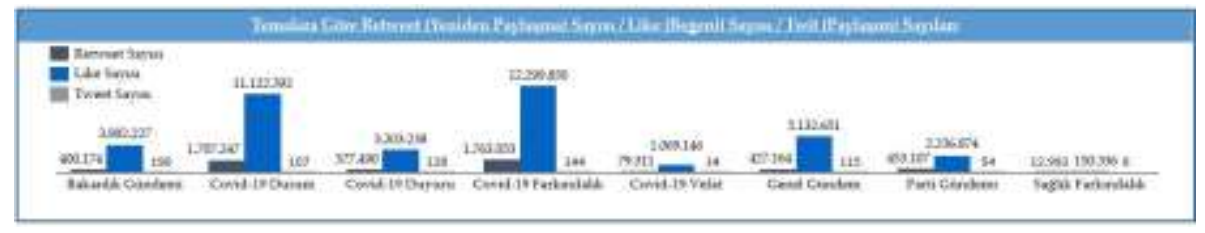

Şekil 6. 10 Ocak-31 Mayıs 2020 tarihleri arasındaki paylaşımların temalara göre aylık dağılımı

Kriz iletişimi stratejisinde proaktif ve reaktif alanda bir araç olarak konumlandırılan paylaşımlara bakıldığında, Covid-19 Duyuru ve Covid-19 Durum temalarını görmekteyiz. Özellikle Covid-19 duyuru kriz öncesi iletişimde önemli bir içerik paylaşımını mümkün kılmıştır. Ancak, Covid-19 Duyuru paylaşımları ( $\mathrm{N}=128)$ 3,202,238 beğeni ve 377,490 yeniden paylaşma sayılarına ulaşırken, Covid-19 Durum temasındaki sayıca daha az olan paylaşımlar (N=107) 11,122,392 beğeni ve 1,707,247 yeniden paylaşma sayılarıyla en çok etkileşim alan tema olmuştur. Burada, Bakan Koca'nın içerik paylaşımlarında özellikle reaktif kriz iletişiminde takipçilere başarılı şekilde erişildiği görülmektedir.

\section{Tartışma ve Sonuç}

Araştırma sonuçları göstermiştir ki, bir sosyal ağ platformu olarak Twitter, gündemin gereklilikleri bağlamında eş zamanlı olarak sağlık, kriz ve siyasal iletişim uygulamalarında araç olarak kullanılmıştır.

Araştırmanın örneklemini oluşturan Dr. Fahrettin Koca'ya ait paylaşımları incelediğimizde, analizler sonucu şu sonuçlara ulaşılmıştır:

Dr. Fahrettin Koca'nın Twitter'daki takipçi sayısı, Twitter'ın ağırlıklı olarak siyasal iletişim aracı olarak kullanıldığı dönemde görece yavaş bir artış sergilerken, kriz ve sağlık iletişimine dair içerik paylaşımlarının başladığ Ocak 2020'den itibaren artış hızlanmaya başlamış, Mart 2020'de ise doruk noktasına ulaşmıştır. Takipçi sayısındaki bu artış, gündemdeki krizin sağlık 
alanında olması sebebiyle Twitter'da Dr. Fahrettin Koca'nın hem sağlık hem kriz iletişiminde güvenilir bir bilgi/iletişim kaynağı olarak konumlandığına işaret eder.

Dr. Fahrettin Koca'nın paylaşım sayısında kriz yönetimi döneminde büyük bir artış yaşanmamıştır. Ancak, siyasal iletişim ağırlıklı paylaşımların oranı azalmış, sağlık ve kriz iletişimi odaklı paylaşımların oranı artmıştır. Gündemin gerektirdiği, hedef kitlenin ihtiyaç duyduğu ve iletişim stratejilerinin önceliklendirdiği şekilde bir dağılım olduğu görülmektedir.

Dr. Fahrettin Koca'nın siyasal iletişim amaçlı paylaşımlarının, gündemin kriz ve sağlık olduğu dönemde bile - her ne kadar genel dağılımdaki payı azalsa bile-devamlılık arz ettiği görülmektedir. Bu durum, internet ve sosyal medyanın uygulamalara entegre olmasıyla birlikte, siyasal iletişimin süreklilik arz etmesi gerekliliğine örnek teşkil etmektedir.

Dr. Fahrettin Koca'nın Ocak-Mayıs 2020 ayları arasında yaptığı paylaşımların aldığı etkileşimlere bakıldığında ise, sağlık iletişimiyle ilintilendirilen Covid-19 Farkındalık teması ile kriz iletişimi ile ilintilendirilen Covid-19 Durum temasındaki paylaşımların en çok etkileşim alan paylaşımlar olduğu görülmektedir.

Ülke ve dünya gündemini birçok alanda etkileyen, bütüncül yönetim ve iletişim stratejilerini zorunlu kılan krizler, stratejik iletişim alanında farklı uygulama alanlarının bütüncül bir stratejiyle hareket etmesi gerekliliğini doğurur. Kriz anında sözcü konumunda kişi, eğer kurumsal yönetimde birden çok rolü üstlenmiş ise, tüm bu rollerle ilintili stratejileri bütüncül şekilde değerlendirmeli ve uygulamaların yine bütüncül bir yaklaşımla şekillendirmelidir. Dr. Fahrettin Koca, Covid-19 pandemisi süresince, sağlık alanında tanınan bir bilim insanı, siyasal aktör ve kriz sözcüsü kimliklerini aynı anda üstlenip, tüm bu kimliklerle ilişkili stratejileri bütüncül şekilde yürütmek durumunda kalmıştır. Araştırma bünyesinde belirli zaman aralığında ve tek bir sosyal ağ platformu üzerinden yapılan çalışma özelinde, Dr. Koca'nın Twitter'ı üç farklı iletişim alanında dengeli ve efektif şekilde araçsallaştırdığı söylenebilir. 


\title{
EXTENDED ABSTRACT
}

\section{Simultaneous Instrumentation of Twitter in Different Communication Practices: The Analysis of Dr. Fahrettin Koca's Twitter Posts in Covid-19 Pandemic}

\author{
A. Elif Posos Devrani \\ Turkish-German University
}

In this study, as a political figure who has been in the spotlight, the Republic of Turkey's Health Minister, Dr. Fahrettin Koca's Twitter use during the Covid-19 crisis has been studied. It has also been examined to observe if he has been using this platform for multiple intents as a tool in different types of strategic areas. Dr. Fahrettin Koca and their team had been obliged to integrate their use of political communication practices, crisis communication tools to be conducted simultaneously in the sense of the disastrous nature of COVID-19. It affected the whole wide world. The instrumentalization of Twitter usage for strategically combined communication purposes creates the foundation and pivotal center of this research.

Political -/health - and crisis communication are considered under the "communication" umbrella with methodological, processual, and instrumental similarities. On the other hand, it is easily possible for these communication areas to target whole different communities because they aim for different kinds of issues and different purposes. The common feature of these communication practices is that they aim for overlapping target audiences in media tools. In other words, a political actor can simultaneously reach their target audience in wellbeing, crisis, and political communication using the same method and tool. The examination of social media platform usage that serves multiple purposes in this article focuses on the early COVID-19 era of Turkey. Dr. Fahrettin Koca's posts on their Twitter account were examined as health- / political -/crisis communication tools.

In this study, a mixed-method was used as a tool. Initial level examination of these two leveled analyses was to evaluate Dr. Fahrettin Koca's Twitter account's (@drfahrettinkoca) post/like/repost data quantitatively monthly in the broader period. (1) In the first level, the number of posts by month and 
the interactions between November 26, 2018, to January 19, 2021 were quantitatively compared. Although Dr. Fahrettin Koca signed up for Twitter on July 9 of 2018, Twitonomy, a data collection tool, can extract up to 3200 of the most recent Twitter database posts. Therefore, a limitation for the first phase was encountered, and the 3198 shares from Dr. Fahrettin Koca were taken as groundwork. The updated date range examined from Dr. Fahrettin Koca's Twitter account before and during the pandemic as a tool for health communication and crisis communication purposes gives us meaningful results regarding the numerical change of the initial expected shares and interactions. (2) On the second level, 3198 posts between the dates of January 10 to May 31 of 2020, defined as the crisis period, were subjected to reflexive thematic analysis. The posts from the Minister dating from January 10 to May 31 of 2020 were evaluated on both interaction and content. COVID-19 rates from Turkey were taken into account when deciding on the research dates.

The findings revealed that, as a social networking platform, Twitter had been used as a tool in health, crisis, and political communication activities concurrently in light of the agenda's requirements.

As a result of examining the sample of the research, Dr. Fahrettin Koca's shares, the following conclusions were reached:

- When Twitter was mainly used for political correspondence, Dr. Fahrettin Koca's number of Twitter followers grew slowly. The increase began accelerating starting from January 2020, when his content focus moved mainly on crisis and health communication, and in March 2020, the growth reached its peak point. The increase in the number of followers is a sign that Dr. Koca has become a reliable source of information in both health and crisis communication during the crisis on the agenda.

- There was a significant increase in use in Dr. Fahrettin Koca's social media account during the crisis management period. However, the rate of posts based on political communication decreased while the rate of posts focused on health and crisis communication increased. It is seen that there are needs and distribution requirements from the target audience on the plan, and the communication strategies prioritize it.

- It can be seen that Koca's political content had been still being posted on his account even during the agenda was being focused on health and crisis - even though the number of political tweets was minimized -. This 
situation exemplifies the necessity of the continuity in political communication and the integration of the internet and social media networks.

- When looking at the interactions of Koca's posts between January and May 2020, it is seen that the COVID-10 awareness themed and the crisis communication themed posts which are associated with health communication, are the most interaction attracted content from his Twitter account.

Crises, which affect the whole country's agenda, make it pivotal to use integrated management and communication strategies, making the strategic communication field move within a holistic approach a necessity. Suppose a spokesperson in a position of governance takes on several positions during a crisis. In that case, they should be assessing their strategy in light of these roles and shape their practices with a holistic approach. During the COVID-19 pandemic, Fahrettin Koca had to adopt the identities of a scientist, political actor, and a well-known crisis spokesperson in the field of health while simultaneously maintaining all of these identities and carry out his strategies in a holistic manner. In the context of this study being conducted over a specific time on a single social media platform, it can be said that Dr. Koca's Twitter use was balanced and effective in all three separate communication fields.

\section{Kaynakça / References}

Ateş, N. B., ve Baran, S. (2020). Kriz iletişiminde sosyal medyanın etkin kullanım: covid19 (koronavirüs) salgınına yönelik twitter analizi. Kocaeli Üniversitesi IIletişim Fakültesi Araştırma Dergisi, 16, 66-99. https://dergipark.org.tr/en/pub/kilad/issue/57944/787103

Aziz, A. (2011). Siyasette etkili iletişim teknikleri (1. basım). Başlık Yayın Grubu: 38 Kişisel Gelişim; 01. Başlık Yayınları.

Aziz, A. (2014). Siyasal İletişim (5.basım). Yayın no İetişim yayınları dizisi: Vol. 22. Nobel Yayın Dağıtım.

Boyatzis, R. E. (1998). Transforming qualitative information: Thematic analysis and code development. Sage Publications.

Braun, V., ve Clarke, V. (2006). Using thematic analysis in psychology. Qualitative Research in Psychology, 3(2), 77-101. https://doi.org/10.1191/1478088706qp063oa

Braun, V., ve Clarke, V. (2019). Reflecting on reflexive thematic analysis. Qualitative Research in Sport, Exercise and Health, 11(4), 589-597. https://doi.org/10.1080/2159676X.2019.1628806 
Braun, V., Clarke, V., Hayfield, N., eTerry, G. (2019). Thematic analysis. In P. Liamputtong (Ed.), Handbook of Research Methods in Health Social Sciences içinde (s. 843-860). Springer Singapore. https://doi.org/10.1007/978-981-10-5251-4_103

Coombs, W. T. (2014). Ongoing crisis communication: Planning, managing, and responding: University of Central Florida (Fourth edition). Sage Publications.

Coombs, W. T., ve Holladay, S. J. (Eds.). (2012). Handbooks in communication and media: The handbook of crisis communication. Wiley-Blackwell. https://doi.org/10.1002/9781444314885

Çınarlı, İ. (2016). Stratejik sağlık iletişiminin sağlı̆̆ın tıbbileşmesindeki rolü. İletişim Kuram ve Araştırma Dergisi, 43. https://iletisimdergisi.hacibayram.edu.tr/index.php/1kad/article/view/303

Guest, G., MacQueen, K. M., ve Namey, E. E.(Eds.). (2012). Applied thematicanalysis. SAGE. Heldman, A. B., Schindelar, J., ve Weaver, J. B. (2013). Social media engagement and public health communication: Implications for public health organizations being truly "social". Public Health Reviews, 35(1). https://doi.org/10.1007/BF03391698

Hootsuite and We are Social. (2021). \#Digital2021 Turkey. https://datareportal.com/reports/digital-2021-turkey

McNair, B. (2017). An introduction to political communication (6th edition). Communication and society. Routledge.

Sağlık Bakanı Koca Türkiye'de ilk koronavirüs vakasının görüldüğünü açıkladı. (2020, Mart 11). Anadolu Ajansı. https://www.aa.com.tr/tr/koronavirus/saglik-bakanikoca-turkiyede-ilk-koronavirus-vakasinin-goruldugunu-acikladi/1761466

SocialBlade.com. (2020). Twitter stats summary: User statıstıcs for. https://socialblade.com/twitter/user/drfahrettinkoca

Yener, D. (2020, March 24). Türkiye'nin koronavirüsle mücadele politikasına 'Bilim Kurulu' yön veriyor. Anadolu Ajansı. https:/www.aa.com.tr/tr/koronavirus/turkiyenin-koronavirusle-mucadele-politikasina-bilim-kurulu-yon-veriyor/1777215

\section{Kaynakça Bilgisi / Citation Information}

Posos Devrani, A. E. (2021). Twitter' ın farklı iletişim uygulamalarında eşzamanlı araçsallaşması: Covid-19 pandemisinde Dr. Fahrettin Koca'nın twitter paylaşımlarının analizi. OPUS-Uluslararası Toplum Araştırmaları Dergisi, 17(Pandemi Özel Sayısı), 3522-3541. DOI: 10.26466/opus.884602 